\section{EUROPEAN MOBILITY SCHEME FOR PHYSICS STUDENTS Scheme Launched}

We have reported on previous occasions [EN 22 (1991) 82, 114] on the European Physical Society's plans to establish, together with universities and equivalent institutions throughout Europe, a mobility scheme for physics students. Based on the positive response to consultations with physics departments (see accompanying item), the Council of EPS decided in Athens last March to launch the scheme. A Convention and the implementation schedule detailed alongside were approved.

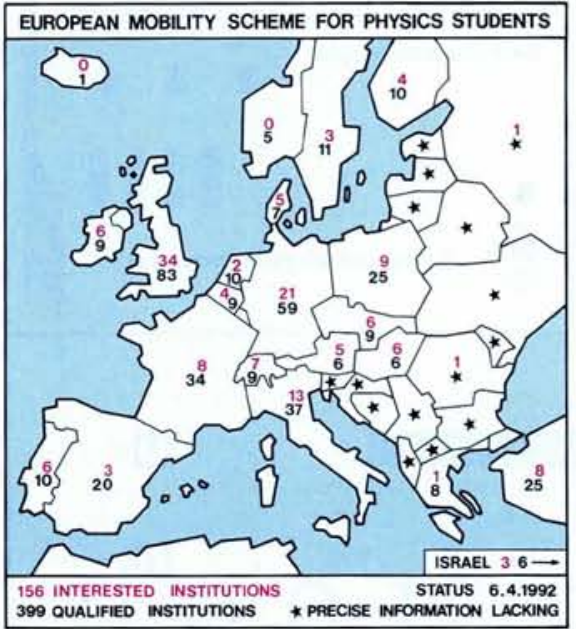

\section{Positive Response}

The EPS Mobility Working Group sent a questionnaire in October 1991 to 182 institutions teaching first-degree courses in physics in order to gauge the interest in a European student mobility scheme. Some 156 institutions replied positively and only 8 gave a "no". The main results were:

- $98 \%$ agreed to the openness of the scheme whereby all appropriate European institutions could participate;

- $90 \%$ would limit the number of students accepted (an average of 7 places per institution was offered):

- $81 \%$ agreed to the convention without modification

- $56 \%$ agreed to English only for information exchange and $38 \%$ wanted both English and the local working language;

- $52 \%$ of institutions could immediately provide students with access to international computer networks.

\section{What Are the Major Problems?}

Several responding institutions, notably in the UK where English is invariably the working language, expressed concern about unbalanced flows of students. Financial difficulties could arise for institutions which depend heavily on student fees. The solution here is to set a suitably low limit to the number of students accepted.

\section{IMPLEMENTATION SCHEDULE}

22 April 1992: mailing

Designated "contact persons" in institutions interested in the scheme were sent on 22 April 1992 all the relevant documents for joining the scheme. They comprised the Convention, an information package and a model of a "request for adherence" letter. 31 August 1992: adherence request

Institutions interested in joining the scheme should send the letter requesting adherence to the Executive-Secretary of EPS by 31 August 1992

\section{October 1992: acceptance}

Institutions which have requested adherence will be informed before 31 October 1992 of acceptance into the mobility scheme by a Mobility Committee formed by enlarging the present Working Group. Contact Persons will also be asked to send information concerning academic and practical aspects.

31 January 1993: database operational

All the relevant information needed to run the scheme must have been entered by participating institutions into a computerised mobility database by 31 January 1993, the date the database becomes operational. Spring 1993: students select courses

Students consult the database, choose their host institution and establish the study programme which a Coordinator in each home institution must approve.

It is anticipated that courses will generally be given in the local working language so most students will have to accept the need for foreign language skills. Participating institutions can help by providing language preparation.

Some institutions will probably only accept students taking more advanced courses (say third and fourth year).

Grants and other practical help such as prearranged accommodation are often necessary to permit a student to participate in mobility schemes. Institutions will be urged to ensure essential local measures are undertaken and much will depend on the devotion of each institution's coordinator

\section{What About Your Institution?}

The questionnaire was sent mainly to those institutions which replied positively to a April 1991 call for expressions of interest. Excluding Albania, Bulgaria, Estonia, Latvia, Lithuania, Romania, the former Yugoslav Republic, and the CIS for which reliable information is lacking, there are thought to be about 400 qualified institutions of which $39 \%$ sent positive answers (see figure). The Working Group realises that all these institutions have certainly not yet been contacted at the appropriate level. So readers working in an academic institution are asked to ensure that their authorities are aware of the mobility scheme.

\section{Summer 1993: students informed}

Students' files will be transmitted to the intended host institution which will inform each student of acceptance or refusal as soon as possible.

October 1993: scheme operational

Accepted students begin their studies in another country.

Notes:

- Participating institution: some institutions teach physics in different departments, but generally speaking there is one central body that can act on their behalf for the purposes of the scheme. The Contact Person would in most cases be attached to this body.

- Database: Dr. M.G. James of the Physics Department, University of Manchester, UK, is in the process of setting up a computerised database. Real-time remote access wil be possible using a PC or other computer connected as a terminal to an internationa network or to a dial-up (modem) PTT link. - Mobility grants: mobility grants to cover additional expenses for students will hope fully be available. All institutions will be asked to seek national and institutional sup port. The Mobility Committee will apply to international programmes with the help of designated "coordinating institutions". The two main avenues here are Inter-University Cooperation Programmes (ICP) in the European Community's ERASMUS programme for EC and EFTA countries, and Joint European Projects (JEP) in the EC's TEMPUS programme for central and eastern Europe.

\section{FURTHER INFORMATION}

If you are interested in the EPS mobility scheme but have no detailed information, please first check with your department head to see if contacts with your institution have already been established.

If your department head appears not to be informed, please do one of the following - contact the EPS Secretariat in either Geneva or Budapest (see inside front cover for addresses, telephone and fax numbers, and e-mail address)

- fill in and send to the Geneva Secretariat a copy of the coupon given below.

Please send me the documentation regarding the European Mobility Scheme for Physics Students.

\section{Institution :}

Title \& Name:

Position:

Address:

Tel:

Fax:

E-mail:

Signature \& date:

Send to:

EPS, POB 69, CH-1213 Petit-Lancy 2 (Fax: +41-22-793 13 17) 